Borneo Journal of Sciences and Technology, Volume (1), Issue (2), Pages: 16-26

DOI: https://doi.org/10.35370/bjost.2019.1.2-03

e-ISSN: 2672-7439

(C) 2019, UCTS Publisher.

$\begin{array}{lll}\text { Submitted: } 11^{\text {th }} \text { April } 2019 & \text { Accepted: } 30^{\text {th }} \text { April } 2019 & \text { Published: } 31^{\text {st }} \text { July } 2019\end{array}$

\title{
Incorporating Lightweight Materials in Reinforced Concrete Beams and Slabs - A Review
}

\author{
Yong Tat Lim, Jen Hua Ling \\ School of Engineering and Technology, University College of Technology Sarawak, 96000, Sibu, \\ Sarawak, Malaysia
}

\begin{abstract}
This paper reviews the structural performances of reinforced concrete beams and slabs filled with lightweight materials to identify the research gaps in the area for future research development. Data is extracted from the research works done by different researchers. It was then recomputed to analyze the effects of concrete replacement regions, geometrical properties and spacing of lightweight materials on the ultimate strength of the structural elements. The lightweight materials were found to be more effective in reducing the weight of the slab without significantly affecting its strength as compared with the beam. The lightweight materials are recommended to have round corners, spaced out and positioned at the neutral axis or the compressive region for better strength performance so that the effective strength to weight ratio exceeds 1.0.
\end{abstract}

Keywords: Reinforced concrete, lightweight system, beam, slab, structural performance

\section{INTRODUCTION}

Reinforced concrete structure is widely used in the construction industry of Malaysia. It is constructed into skeleton frames comprising slabs and beams, which are the horizontal members in the forms of flat surface and longitudinal section, respectively. These members are used to sustain the loads acting on a building [1]. Since the permanent load constitutes a large portion of the design load, the construction cost could be reduced by using lightweight beams and slabs.

In the 2010s, lightweight slabs, such as bubble deck slab, gained popularity in Malaysian construction industry. This revolutionary design removes the nonperforming concrete from the neutral axis of a solid slab to provide a comparable bending strength at a $30 \%$ lighter weight [2].

The principle is thought applicable to reinforced concrete beams. Although numerous studies have been conducted [3, 4], an efficient lightweight beam design with a decent strength to volume ratio is yet to be found. For some reasons, the beams generally lose more strength than the concrete reduction in percentage. Since the working principles between beam and slab are quite identical, it is still possible to produce lightweight beam by removing some portions of the nonperforming concrete.

This paper reviews the research related to the lightweight slabs and beams. This discusses the effect of the regions where concrete is replaced with lightweight materials, the geometrical properties and the spacing between the lightweight materials as these factors significantly influence the behaviour of lightweight structures. On top of those, the gaps of knowledge are identified and the potential applications of such system are also projected in this paper.

\section{METHOD}

The literature investigation was carried out by screening through a series of studies that incorporated lightweight materials in reinforced concrete slabs and beams. The papers which were relevant, had a primary purpose of investigating the strength performance of the lightweight elements, and reported on their own results without the secondary data were selected for review. Subsequently, data (i.e. ultimate strength and volume of lightweight materials in the structural elements) was extracted from the research works and recomputed into the effective strength to weight ratio to evaluate the efficiency of the elements. The computed results were analyzed and discussed.

\section{PREVIOUS STUDIES ON LIGHTWEIGHT STRUCTURE}

Several studies have been conducted to investigate the performance of a lightweight structure under static loads. The authors' names, year of publication, structure, research method, material, replacement region and shape of material are summaries in Table 1. 
Incorporating Lightweight Materials in Reinforced Concrete Beams and Slabs - A Review

Table 1: Previous studies on lightweight structure

\begin{tabular}{|c|c|c|c|c|c|c|c|c|}
\hline No & Authors & Structure & Method & Material & Region & Shape & $\begin{array}{c}\text { Dimension } \\
(\mathbf{m m})\end{array}$ & Specimen \\
\hline 1 & Ajeel et. al., [3] & Beam & $\mathrm{E}$ & Plastic & $\mathrm{N}$ & Sphere & $\mathrm{d}=90$ & S1 \\
\hline 2 & Chung et. al., [5] & Slab & $\mathrm{E}$ & Plastic & $\mathrm{T}$ & $\begin{array}{l}\text { Donut } \\
\text { Donut }\end{array}$ & $\begin{array}{l}\mathrm{d}=270, \mathrm{D}=50 \\
\mathrm{~d}=270, \mathrm{D}=50\end{array}$ & $\begin{array}{l}\mathrm{S} 2 \\
\text { S3 }\end{array}$ \\
\hline 3 & $\begin{array}{c}\text { Sivaneshan and } \\
\text { Hrishankar [6] }\end{array}$ & Beam & $\mathrm{E}$ & Plastic & $\mathrm{C}$ & $\begin{array}{l}\text { Sphere } \\
\text { Sphere } \\
\text { Sphere } \\
\text { Sphere } \\
\text { Sphere }\end{array}$ & $\begin{array}{l}\mathrm{d}=75 \\
\mathrm{~d}=65 \\
\mathrm{~d}=65 \\
\mathrm{~d}=35 \\
\mathrm{~d}=35\end{array}$ & $\begin{array}{l}\text { S4 } \\
\text { S5 } \\
\text { S6 } \\
\text { S7 } \\
\text { S8 }\end{array}$ \\
\hline 4 & $\begin{array}{c}\text { Wariyatno et. al., } \\
{[7]}\end{array}$ & Slab & $\mathrm{E}$ & $\begin{array}{c}\text { Polystyrene } \\
\text { PVC }\end{array}$ & $\mathrm{T}$ & $\begin{array}{c}\text { Rectangular } \\
\text { Rectangular } \\
\text { Rectangular } \\
\text { Rectangular } \\
\text { Circular } \\
\text { Circular } \\
\text { Circular } \\
\text { Circular }\end{array}$ & $\begin{array}{l}70 \times 300 \\
70 \times 300 \\
70 \times 300 \\
70 \times 300 \\
d=150 \\
d=150 \\
d=150 \\
d=150\end{array}$ & $\begin{array}{c}\text { S9 } \\
\text { S10 } \\
\text { S11 } \\
\text { S12 } \\
\text { S13 } \\
\text { S14 } \\
\text { S15 } \\
\text { S16 }\end{array}$ \\
\hline 5 & $\begin{array}{c}\text { Anju and Joseph } \\
{[8]}\end{array}$ & Beam & $\mathrm{E}, \mathrm{M}$ & Polystyrene & $\mathrm{T}$ & $\begin{array}{c}\text { Vertical } \\
\text { Rectangular }\end{array}$ & $30 \times 108$ & S17 \\
\hline 6 & Kumar and Joy [9] & Beam & $\mathrm{E}$ & Plastic & $\mathrm{T}$ & $\begin{array}{l}\text { Sphere } \\
\text { Sphere }\end{array}$ & $\begin{array}{l}\mathrm{d}=35 \\
\mathrm{~d}=35\end{array}$ & $\begin{array}{l}\text { S18 } \\
\text { S19 }\end{array}$ \\
\hline 7 & $\begin{array}{l}\text { Manikandan, } \\
\text { Dharmar and } \\
\text { Robertravi [10] }\end{array}$ & Beam & $\mathrm{E}$ & Polystyrene & $\mathrm{T}$ & $\begin{array}{c}\text { Square } \\
\text { Circular }\end{array}$ & $\begin{array}{l}70 \times 64 \\
d=75\end{array}$ & $\begin{array}{l}\mathrm{S} 20 \\
\mathrm{~S} 21\end{array}$ \\
\hline 8 & $\begin{array}{l}\text { Ahmad and Hadi } \\
\text { [4] }\end{array}$ & Beam & $\mathrm{E}$ & Polystyrene & $\mathrm{T}$ & $\begin{array}{l}\text { Square } \\
\text { Square } \\
\text { Square } \\
\text { Square }\end{array}$ & $\begin{array}{l}40 \times 40 \\
40 \times 40 \\
80 \times 40 \\
80 \times 40\end{array}$ & $\begin{array}{l}\text { S22 } \\
\text { S23 } \\
\text { S24 } \\
\text { S25 }\end{array}$ \\
\hline 9 & Izzat et al., [11] & Slab & $\mathrm{E}$ & Polystyrene & $\mathrm{T}$ & $\begin{array}{l}\text { Rectangular } \\
\text { Rectangular } \\
\text { Rectangular } \\
\text { Rectangular } \\
\text { Rectangular } \\
\text { Rectangular } \\
\text { Rectangular } \\
\text { Rectangular } \\
\text { Rectangular }\end{array}$ & $\begin{array}{c}75 \times 50 \\
75 \times 70 \\
75 \times 100 \\
50 \times 50 \\
50 \times 70 \\
50 \times 100 \\
40 \times 50 \\
40 \times 70 \\
40 \times 100 \\
\end{array}$ & $\begin{array}{l}\text { S26 } \\
\text { S27 } \\
\text { S28 } \\
\text { S29 } \\
\text { S30 } \\
\text { S31 } \\
\text { S32 } \\
\text { S33 } \\
\text { S34 } \\
\end{array}$ \\
\hline 10 & $\begin{array}{l}\text { Jesudhason and } \\
\text { Hemalatha [12] }\end{array}$ & Beam & $\mathrm{E}$ & Polystyrene & $\mathrm{T}$ & $\begin{array}{c}\text { Square } \\
\text { Horizontal } \\
\text { Rectangular }\end{array}$ & - & $\begin{array}{l}\text { S35 } \\
\text { S36 }\end{array}$ \\
\hline 11 & $\begin{array}{c}\text { Joy and Rajeev } \\
{[13]}\end{array}$ & Beam & $\mathrm{E}, \mathrm{M}$ & PVC & $\mathrm{N}$ & $\begin{array}{l}\text { Circular } \\
\text { Circular }\end{array}$ & $\begin{array}{l}\mathrm{d}=40 \\
\mathrm{~d}=50\end{array}$ & $\begin{array}{l}\text { S37 } \\
\text { S38 }\end{array}$ \\
\hline 12 & Ibrahim et. al., [14] & Slab & $\mathrm{E}$ & Plastic & $\mathrm{T}$ & $\begin{array}{l}\text { Sphere } \\
\text { Sphere } \\
\text { Sphere } \\
\text { Sphere }\end{array}$ & $\begin{array}{c}\mathrm{d}=64 \\
\mathrm{~d}=80 \\
\mathrm{~d}=64 \\
\mathrm{~d}=100\end{array}$ & $\begin{array}{l}\text { S39 } \\
\text { S40 } \\
\text { S41 } \\
\text { S42 } \\
\end{array}$ \\
\hline 13 & Chung et. al., [15] & Slab & $\mathrm{E}$ & Plastic & $\mathrm{T}$ & $\begin{array}{c}\text { Donut } \\
\text { Round Box }\end{array}$ & $\begin{array}{c}\mathrm{d}=270, \mathrm{D}=50 \\
\mathrm{~d}=270\end{array}$ & $\begin{array}{l}\text { S43 } \\
\text { S44 }\end{array}$ \\
\hline 14 & Chung et. al., [16] & Slab & $\mathrm{M}$ & Plastic & $\mathrm{T}$ & $\begin{array}{c}\text { Square } \\
\text { Sphere } \\
\text { Ellipse } \\
\text { Rect Donut } \\
\text { Rect Donut } \\
\text { Round Rect } \\
\text { Round Rect } \\
\text { Mushroom }\end{array}$ & $\begin{array}{c}27 \times 14 \\
d=14 \\
d=27 \\
d=27, D=50 \\
d=27, D=30 \\
d=27, R=70 \\
d=27, R=50 \\
d=27\end{array}$ & $\begin{array}{l}\text { S45 } \\
\text { S46 } \\
\text { S47 } \\
\text { S48 } \\
\text { S49 } \\
\text { S50 } \\
\text { S51 } \\
\text { S52 }\end{array}$ \\
\hline
\end{tabular}

*Note: $\mathrm{E}=$ experiment, $\mathrm{M}=$ numerical modelling; 
$\mathrm{C}=$ compression, $\mathrm{N}=$ neutral, $\mathrm{T}=$ tension;

$\mathrm{d}=$ diameter, $\mathrm{D}=$ internal diameter, $\mathrm{R}=$ corner radius.

The specimen number is assigned by the author, in comparison to their respective design.

Most of the studies in Table 1 focuses on the experimental study rather than numerical modelling. Test specimens were normally fabricated into a manageable scale and tested in the laboratory. Experiments, if properly conducted, can give reliable results, and the mode of failure can be observed.

For the difficulties and challenges of numerical models to closely resemble the response of an actual element, particularly when the element constitutes various types of materials with different properties and the response is governed by the interactions between such materials, numerical modelling is less preferred. A typical numerical model is normally calibrated and verified through experiments. It is foreseen that numerical modelling would be more popular when (a) the predicted response can reliably resemble the reality, and (b) the resource (i.e. time, cost and manpower) consumed to acquire results is significantly lower than experimental study. This shall realize in future when researchers gain a better understanding of the finite element method, and the performance of computing system upgrades significantly.

\section{DEFINITION OF LIGHTWEIGHT}

The term "lightweight" has been extensively adopted by the researchers in the field of reinforced concrete structure without a clear-cut definition. It is generally understood that lightweight structure refers to the building structure which has a lower density than control structure.

In a broader context, beam and slab are considered lightweight when it is lighter than the solid reinforced concrete beam and slab. The percentage of weight reduction, $W$, can be calculated using Eq. (1).

$$
W=\frac{w_{C}-w_{L}}{w_{C}} \times 100 \%
$$

where: $W_{C}$ is the weight of control structure

$W_{L}$ is the weight of lightweight structure

However, lightweight beams and slabs generally have a lower strength (Eq. (2)). Thus, the performance of the lightweight element shall be evaluated in terms of the efficiency of materials used. With that, an element is considered effective when it offers a comparable strength as a solid element at a lighter selfweight (Eq. (3)).

The percentage of strength reduction, $S$, can be calculated as:

$$
S=\frac{s_{C}-s_{L}}{s_{C}} \times 100 \%
$$

where: $S_{C}$ is the ultimate strength of control structure $S_{L}$ is the ultimate strength of lightweight structure.

Hence, the effective strength to weight ratio, $E$ is computed as:

$$
E=\frac{100-s}{100-W}
$$

where: $S$ is the percentage of strength reduction

$W$ is the percentage of weight reduction.

Table 2 shows the percentage of weight reduction, $W$, percentage of strength reduction, $S$, and effective strength to weight ratio, $E$, which are computed from the test results given by the respective authors in Table 1 , in comparison to their solid specimens. The computed results are presented graphically in Figures 1 and 2 for the lightweight beams and slabs, respectively.

The lightweight element is considered effective when the effective strength to weight ratio, $E$, is more than 1 . If the element loses more strength than its weight $(E<1.0)$, it is considered ineffective.

From Table 2, it is found that:

a. Most of the lightweight beam (47.4\%) and slab (58.6\%) achieve at least $10 \%$ and $20 \%$ of weight reduction.

b. The weight of beam and slab reduced $28.97 \%$ and $45.00 \%$, while the strength reduced $33.33 \%$ and $17.05 \%$, respectively. Lightweight slabs generally perform better than the beams in terms of effectiveness.

c. For the lightweight slabs, $6.9 \%$ of them has the effective strength to weight ratio greater than 1.5, $72.4 \%$ ranged from 1.0 to 1.5 , and the remaining $(20.7 \%)$ were less than 1.0

d. As for lightweight beam, none achieved the effective strength to weight ratio of $1.5 .31 .6 \%$ of them ranged from 1.0 to 1.5 and the majority of them $(68.4 \%)$ were lower than 1 .

It seems that the effective strength to weight ratio for lightweight slabs barely exceeds 1.5 , and the removal of concrete from a beam is likely to notably affect its efficiency. It would be a breakthrough if the efficiency of the lightweight slab and beam could be further increased, probably through optimization in terms of the region of concrete replacement, geometrical properties and spacing between the lightweight materials, as discussed in the following sections. 
Incorporating Lightweight Materials in Reinforced Concrete Beams and Slabs - A Review

Table 2: Performance of lightweight structure

\begin{tabular}{|c|c|c|c|c|c|c|}
\hline No & Authors & Structure & Specimen & $\begin{array}{c}\text { Percentage of } \\
\text { weight reduction } \\
(\%)\end{array}$ & $\begin{array}{l}\text { Percentage of } \\
\text { strength } \\
\text { reduction }(\%)\end{array}$ & $\begin{array}{c}\text { Effective strength to } \\
\text { effective weight } \\
\text { ratio }\end{array}$ \\
\hline 1 & Ajeel et. al., [3] & Beam & S1 & 10.00 & 11.18 & 0.99 \\
\hline \multirow[t]{2}{*}{2} & Chung et. al., [5] & Slab & $\mathrm{S} 2$ & - & 5.33 & - \\
\hline & & & S3 & - & 1.08 & - \\
\hline \multirow[t]{5}{*}{3} & Sivaneshan and & Beam & S4 & 10.00 & 7.80 & 1.02 \\
\hline & Hrishankar [6] & & S5 & 6.00 & 12.39 & 0.93 \\
\hline & & & S6 & 12.00 & 15.53 & 0.96 \\
\hline & & & S7 & 2.00 & 13.92 & 0.88 \\
\hline & & & S8 & 6.00 & 2.65 & 1.04 \\
\hline \multirow[t]{8}{*}{4} & Wariyatno et. al., & Slab & S9 & 25.45 & 14.39 & 1.15 \\
\hline & [7] & & S10 & 25.45 & 25.33 & 1.00 \\
\hline & & & S11 & 25.45 & 33.25 & 0.90 \\
\hline & & & $\mathrm{S} 12$ & 25.45 & 31.25 & 0.92 \\
\hline & & & S13 & 23.94 & 30.79 & 0.91 \\
\hline & & & S14 & 23.94 & 44.10 & 0.73 \\
\hline & & & S15 & 23.94 & 67.54 & 0.43 \\
\hline & & & S16 & 23.94 & 56.14 & 0.58 \\
\hline 5 & $\begin{array}{c}\text { Anju and Joseph } \\
{[8]}\end{array}$ & Beam & S17 & 8.22 & 3.60 & 1.05 \\
\hline \multirow[t]{2}{*}{6} & Kumar and Joy [9] & Beam & S18 & 4.00 & 7.11 & 0.97 \\
\hline & & & S19 & 8.00 & 16.29 & 0.91 \\
\hline \multirow[t]{2}{*}{7} & Manikandan, & Beam & S20 & 11.95 & 6.96 & 1.06 \\
\hline & $\begin{array}{l}\text { Dharmar and } \\
\text { Robertravi [10] }\end{array}$ & & S21 & 11.78 & 2.61 & 1.10 \\
\hline \multirow[t]{4}{*}{8} & Ahmad and Hadi & Beam & S22 & 7.40 & 37.14 & 0.68 \\
\hline & {$[4]$} & & S23 & 7.40 & 33.33 & 0.72 \\
\hline & & & S24 & 14.80 & 60.00 & 0.47 \\
\hline & & & $\mathrm{S} 25$ & 14.80 & 55.00 & 0.53 \\
\hline \multirow[t]{9}{*}{9} & Izzat et al., [11] & Slab & S26 & 12.80 & 6.60 & 1.07 \\
\hline & & & S27 & 12.80 & 8.70 & 1.05 \\
\hline & & & S28 & 12.80 & 11.00 & 1.02 \\
\hline & & & S29 & 12.80 & 2.00 & 1.12 \\
\hline & & & S30 & 12.80 & 3.00 & 1.11 \\
\hline & & & S31 & 12.80 & 6.00 & 1.08 \\
\hline & & & S32 & 13.70 & 1.40 & 1.14 \\
\hline & & & S33 & 13.70 & 2.20 & 1.13 \\
\hline & & & S34 & 13.70 & 4.40 & 1.11 \\
\hline \multirow[t]{2}{*}{10} & Jesudhason and & Beam & S35 & 13.79 & 41.67 & 0.68 \\
\hline & Hemalatha [12] & & S36 & 28.97 & 33.33 & 0.94 \\
\hline \multirow[t]{2}{*}{11} & Joy and Rajeev & Beam & S37 & 2.30 & 2.96 & 0.99 \\
\hline & [13] & & S38 & 3.60 & 3.76 & 1.00 \\
\hline \multirow[t]{4}{*}{12} & Ibrahim et. al., [14] & Slab & S39 & 25.00 & 0.36 & 1.33 \\
\hline & & & S40 & 29.00 & 11.05 & 1.25 \\
\hline & & & S41 & 24.00 & 0.42 & 1.31 \\
\hline & & & S42 & 30.00 & 10.33 & 1.28 \\
\hline \multirow[t]{2}{*}{13} & Chung et. al., [15] & Slab & S43 & - & 26.09 & - \\
\hline & & & S44 & - & 40.08 & - \\
\hline \multirow[t]{8}{*}{14} & Chung et. al., [16] & Slab & S45 & 45.00 & 17.05 & 1.51 \\
\hline & & & S46 & 20.00 & 1.63 & 1.23 \\
\hline & & & S47 & 28.00 & 1.14 & 1.37 \\
\hline & & & $\mathrm{S} 48$ & 32.80 & 1.22 & 1.47 \\
\hline & & & S49 & 34.00 & 2.50 & 1.48 \\
\hline & & & S50 & 34.60 & 3.61 & 1.47 \\
\hline & & & S51 & 39.60 & 6.64 & 1.55 \\
\hline & & & S52 & 25.00 & 2.94 & 1.29 \\
\hline
\end{tabular}




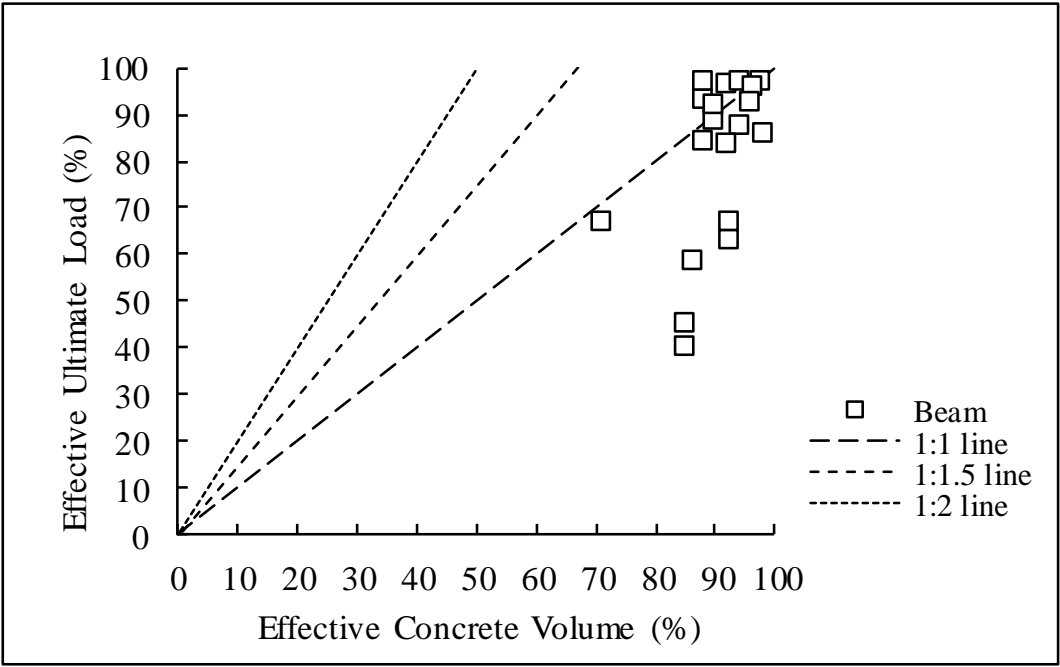

Figure 1: Overview performance of the lightweight beam

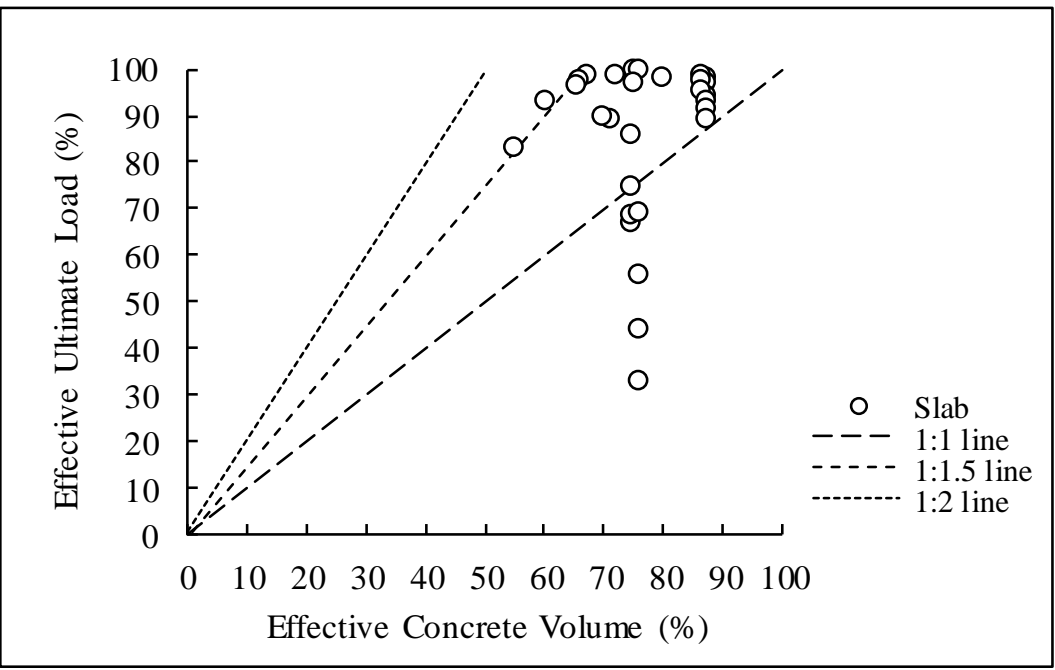

Figure 2: Overview performance of the lightweight slab

\section{REGION FOR CONCRETE REPLACEMENT}

Theoretically, the flexural strength of a reinforced concrete element is governed by the compressive stress of the concrete and the tensile stress of the reinforcement. For relatively small tensile stress offered by concrete in comparison with the steel bars, its contribution to bending resistance is normally ignored.

On the basis of the assumption, the stress distribution of a reinforced concrete element would be as illustrated in Figure 3. The triangular stress distribution is proportional to the stains, which usually occurs under working load conditions during the serviceability limit state. The rectangular-parabolic stress block signifies the distribution of stress at failure when the compressive strains are within the plastic range, which is associated with the ultimate limit state. The equivalent rectangular stress block is a simplified alternative to the rectangular parabolic distribution [17]. 


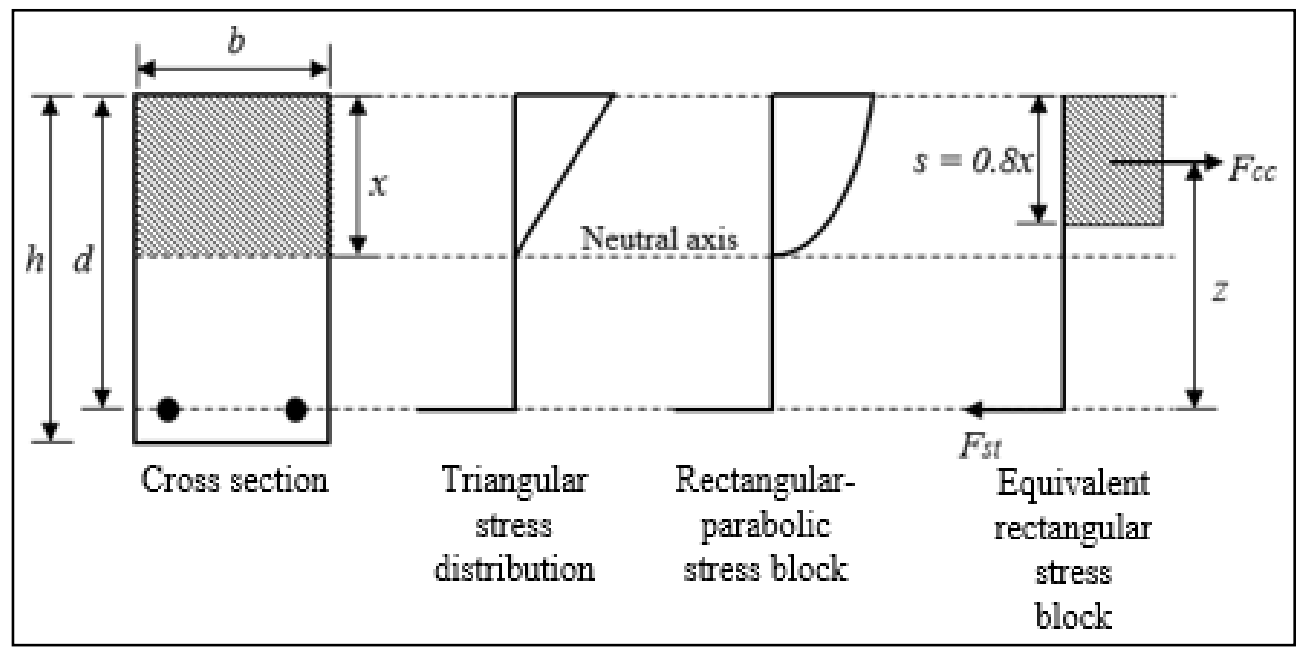

Figure 3: Section and stress diagram

*Note: $h=$ overall height, $d=$ effective depth, $b=$ width of section, $x=$ depth of neutral axis, $s=$ depth of stress block, $z=$ lever arm, $F_{c c}=$ compression force in the concrete, $F_{s t}=$ tensile force in the steel reinforcement

The stress distribution diagram (Figure 3) implies that the concrete below the neutral axis contributes negligible strength to the structure. The concrete in this region could be eliminated without significantly affecting the performance. For that, studies were conducted to replace the concrete in the tension region with lightweight materials $[4,8,9,10,12]$. Under the normal circumstances, the effective strength to weight ratio would be close to 1.0 (Figure 4).

However, the efficiency of the lightweight element can be significantly affected although the concrete in the tension region is replaced, as observed from Figure 4. The lightweight slab fabricated by
Wariyatno et. al. (2017) [7] made of PVC pipes (specimens S14, S15 and S16) demonstrated a significant reduction of strength by more than $40 \%$. This could be due to the brittle properties of PVC pipes, as claimed by the author.

Researchers also tried to replace the concrete at the neutral axis and the compression region $[6,13]$. The effective strength to weight ratio was found in the range of 0.88 to 1.04 (Table 2). This indicates a possibility to replace concrete in this region. However, the relevant publications are limited, and so far, no detail explanation was found on this phenomena.

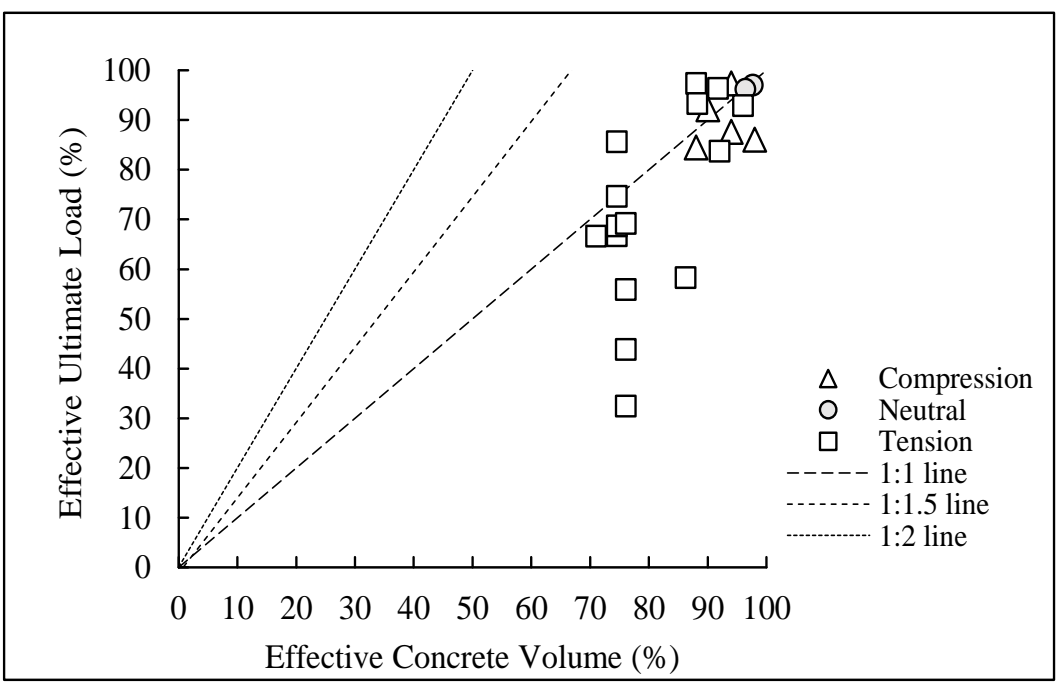

Figure 4: Performance of beam and slab under different concrete replacement region 


\section{GEOMETRY OF LIGHTWEIGHT MATERIALS}

Researchers use lightweight materials in various shapes, such as square, rectangular, sphere, ellipse, donut and etc. to replace concrete in beams and slabs (Figures 5 and 6). The shapes of the lightweight materials seemed to influence the structural performance of beams and slabs.

For lightweight beams, sphere shape gave a more consistent outcome offering the effective strength to weight ratio of about 1.0, and thus, the square shape is less preferred (Figure 5).

For lightweight slabs, sphere, ellipse and donut shapes consistently offered a high degree of efficiency with the effective strength to weight ratio reaching 1.5 (Figure 6). Based on the plotted region for the longitudinal circular shape that scattered from about $30 \%$ to $70 \%$ effective ultimate strength, it is not recommended for the lightweight slab.

In principle, the lightweight materials are preferable without any sharp edge or tip. High stress normally concentrates at the sharp edges and tips, and this makes the beam and slab to be more vulnerable to cracking failure.

Chung et. al. (2009) [16] discovered that the corner radius of the lightweight materials affected $4 \%$ to $17 \%$ of the ultimate strength of the slab. The element's stiffness also increased with the increasing corner radius.

It is worth noting that the concrete penetrating through the hole at the center of the donut shape can influence the slab performance. As the diameter of the hole increased, the slab performance increased by $1.3 \%$ to $4.0 \%$ [16]. With the same cross-sectional area, the specimen with donut shape offered $14 \%$ higher ultimate shear strength than the round box shape [15].

The diameter of lightweight materials is another important factor affecting the structural performance. With the same thickness, the beam with smaller plastic balls $(64 \mathrm{~mm})$ gives a higher flexural capacity compared with the larger plastic balls $(80 \mathrm{~mm})$. The stiffness increased when the volume of the void reduced [14].

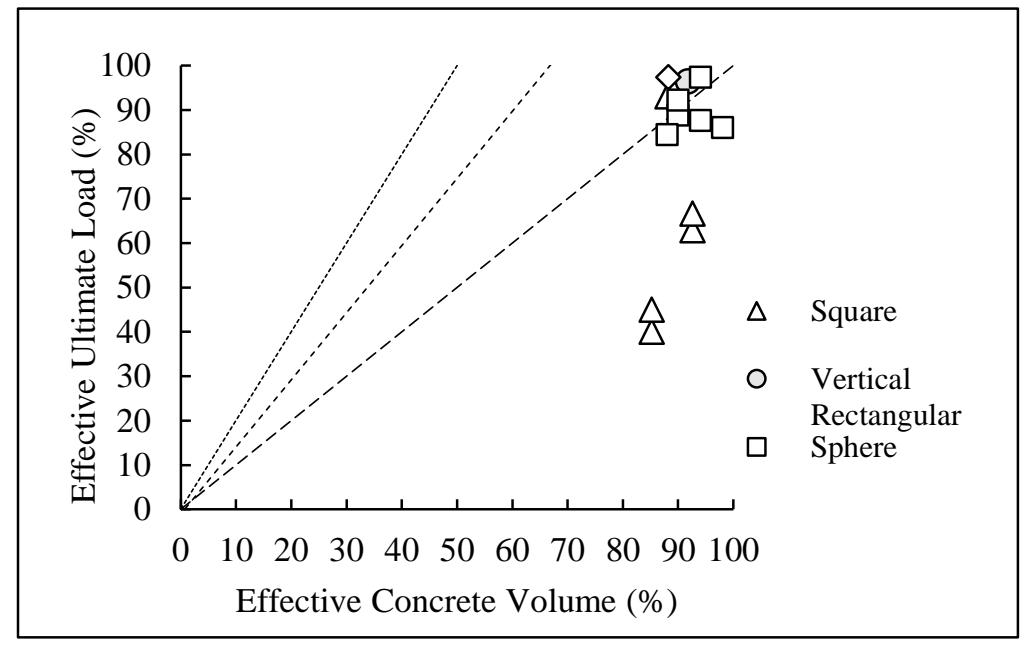

Figure 5: Performance of beam by incorporating various shapes of lightweight materials 


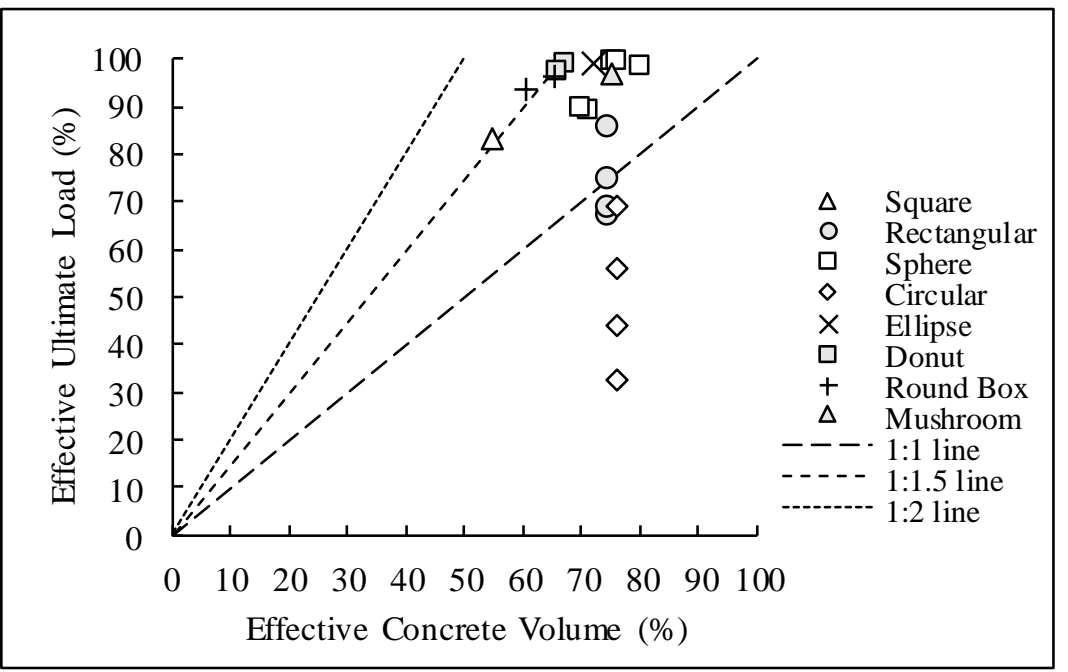

Figure 6: Performance of slab by incorporating various shapes of lightweight materials

\section{SPACING BETWEEN LIGHTWEIGHT MATERIALS}

In the lightweight beams and slabs, the spacing between lightweight materials creates a series of concrete ribs. The concrete ribs allow the distribution of stresses within the element. For the stresses to be more effectively distributed within the structural elements, more and wider concrete ribs are preferred.
The structural performance increased as the number of concrete ribs increased [11]. Despite slight differences in terms of the reduction of concrete volume, the specimens with more number of ribs generally offered $5.2 \%$ to $6.6 \%$ higher strength, as shown in Table 3 and Figure 7.

The stiffness and strength of an element increased when the width of the concrete ribs increased. With the same thickness, the number of cracks increased when the spacing decreased [18].

Table 3: Previous study of spacing between lightweight materials [11]

\begin{tabular}{|c|c|c|c|c|c|c|c|c|}
\hline \multirow[t]{2}{*}{ Element } & \multirow{2}{*}{$\begin{array}{l}\text { Number of concrete } \\
\text { rids in } \\
\text { Z-direction (width) }\end{array}$} & \multicolumn{2}{|c|}{$\begin{array}{c}\text { Dimension of } \\
\text { Polystyrene }(\mathbf{m m})\end{array}$} & \multicolumn{2}{|c|}{$\begin{array}{l}\text { Spacing between } \\
\text { Polystyrene (mm) }\end{array}$} & \multicolumn{2}{|c|}{ Reduction (\%) } & \multirow{2}{*}{$\begin{array}{l}\text { Effective Strength } \\
\text { to Effective } \\
\text { Weight Ratio }\end{array}$} \\
\hline & & Width & Length & Width & Length & Weight & Ultimate Strength & \\
\hline \multirow{9}{*}{ Slab } & 1 & 75 & 50 & 80 & 50 & 12.8 & 6.6 & 1.07 \\
\hline & 1 & 75 & 70 & 80 & 50 & 12.8 & 8.7 & 1.05 \\
\hline & 1 & 75 & 100 & 80 & 50 & 12.8 & 11.0 & 1.02 \\
\hline & 2 & 50 & 50 & 50 & 50 & 12.8 & 2.0 & 1.12 \\
\hline & 2 & 50 & 70 & 50 & 50 & 12.8 & 3.0 & 1.11 \\
\hline & 2 & 50 & 100 & 50 & 50 & 12.8 & 6.0 & 1.08 \\
\hline & 3 & 40 & 50 & 30 & 50 & 13.7 & 1.4 & 1.14 \\
\hline & 3 & 40 & 70 & 30 & 50 & 13.7 & 2.2 & 1.13 \\
\hline & 3 & 40 & 100 & 30 & 50 & 13.7 & 4.4 & 1.11 \\
\hline
\end{tabular}




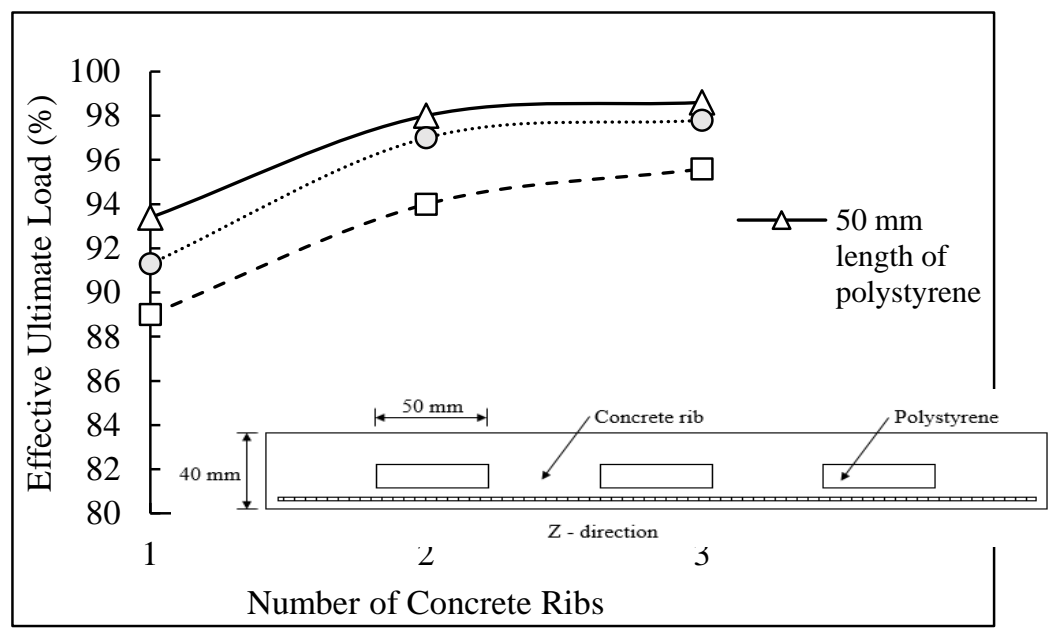

Figure 7: Performance of slab with a different number of concrete ribs [11]

\section{RESEARCH GAPS}

Table 4 summarizes the studies carried out by the researchers for the lightweight beams and slabs. The research seems to be segregating towards the experimental study of a single element (either beam or slab) under the flexural load. Numerical modelling and analytical studies are quite limited thus far. The response of the element under shear load was barely studied. To-date, no study of the combined system of beams and slabs are studied.

It seems the field of study is still at the exploratory stage, where researchers tend to test the response of lightweight beams and slabs with lightweight materials of various shapes. Even so, only one type of shape is used within one structural element. The effects of different shapes in an element is so far not known. Studies could also be conducted to determine the governing parameters and establish the working principles of the lightweight beams and slabs.

The recommendations for future research areas include:-

a. Investigating the behaviour of the combine lightweight beam and slab under incremental static and dynamic loads.

b. Analysing the structural behaviour of beam and slab using the finite element method for a greater variety of shapes. More complex or optimized shapes could easily be tested using computer modelling.

c. Investigating the performance of the beam by replacing the concrete in the areas of $0.8 \mathrm{x}$ from the top surface to the tension region.

d. Incorporating lightweight materials with round corners and a hole at its centre (donut-like shape) in the reinforced concrete elements. e. Increasing the number and width of concrete ribs between the lightweight materials.

f. Deriving models to predict the response of the lightweight slab and beam.

It would be a significant breakthrough if the weight of the beam and slab can be reduced significantly without compromising its structural performance. Should such design proved to be reliable and put into application, probably in the form of the industrialized building systems, the cost of construction could be significantly reduced.

\section{CONCLUSION}

The studies that incorporate lightweight materials in reinforced concrete slabs and beams provide a possible solution to reduce the weight of the structural elements. This paper reviews the relevant research works, which lead to the following conclusions.

The lightweight slab is more effective than the beam in terms of the percentage of weight reduction relative to the strength reduction. A majority of the lightweight slab $(79.3 \%)$ had a higher percentage of weight reduction than strength reduction as compared with the lightweight beam (31.6\%).

The lightweight materials should be placed at the neutral axis and compressive region to yield a consistent ultimate strength. The lightweight materials should have round corners and be spaced out to have more concrete ribs in between the lightweight materials to achieve a higher stiffness and strength of the structural elements. 
Table 4: Analysis of research gap for lightweight system

\begin{tabular}{|c|c|c|c|c|c|c|c|c|c|c|c|c|c|c|c|c|}
\hline 产 & & 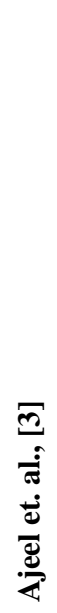 & 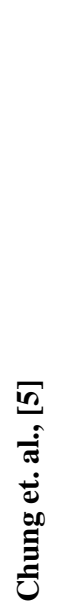 & 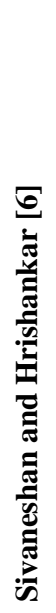 & 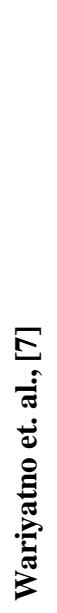 & 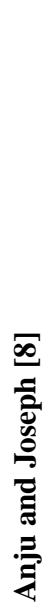 & 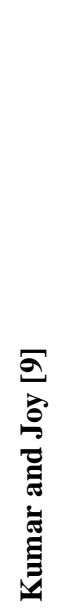 & 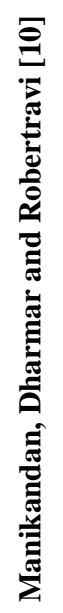 & 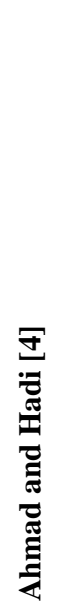 & 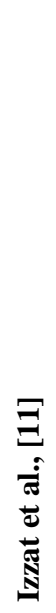 & 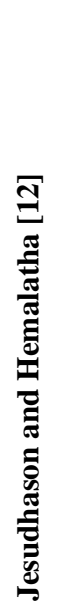 & 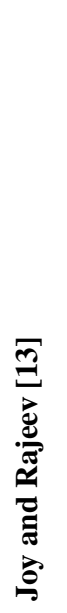 & 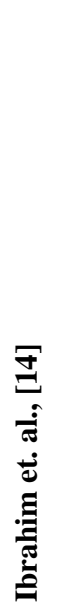 & 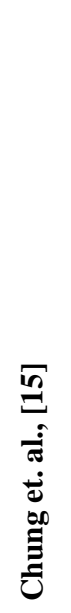 & 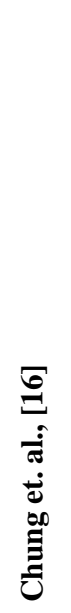 & 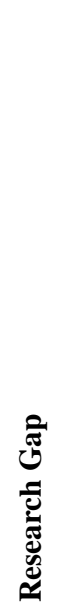 \\
\hline Structure & $\begin{array}{c}\text { Beam } \\
\text { Slab } \\
\text { Beam and Slab }\end{array}$ & $\checkmark$ & $\checkmark$ & $\checkmark$ & $\checkmark$ & $\checkmark$ & $\checkmark$ & $\checkmark$ & $\checkmark$ & $\checkmark$ & $\checkmark$ & $\checkmark$ & $\checkmark$ & $\checkmark$ & $\checkmark$ & $\checkmark$ \\
\hline Behaviour & $\begin{array}{c}\text { Flexural } \\
\text { Shear }\end{array}$ & $\checkmark$ & $\checkmark$ & $\checkmark$ & $\checkmark$ & $\checkmark$ & $\checkmark$ & $\checkmark$ & $\checkmark$ & $\checkmark$ & $\checkmark$ & $\checkmark$ & $\checkmark$ & $\checkmark$ & $\checkmark$ & $\checkmark$ \\
\hline Method & $\begin{array}{l}\text { Experiment } \\
\text { Modelling } \\
\text { Analytical }\end{array}$ & $\checkmark$ & $\checkmark$ & $\checkmark$ & $\checkmark$ & $\checkmark$ & $\checkmark$ & $\checkmark$ & $\checkmark$ & $\checkmark$ & $\checkmark$ & $\checkmark$ & $\checkmark$ & $\checkmark$ & $\checkmark$ & $\begin{array}{l}\checkmark \\
\checkmark\end{array}$ \\
\hline Material & $\begin{array}{c}\text { Plastic } \\
\text { Polystyrene } \\
\text { PVC }\end{array}$ & $\checkmark$ & $\checkmark$ & $\checkmark$ & $\checkmark$ & $\checkmark$ & $\checkmark$ & $\checkmark$ & $\checkmark$ & $\checkmark$ & $\checkmark$ & $\checkmark$ & $\checkmark$ & $\checkmark$ & $\checkmark$ & \\
\hline Region & $\begin{array}{c}\text { Compression } \\
\text { Neutral } \\
\text { Tension }\end{array}$ & $\checkmark$ & $\checkmark$ & $\checkmark$ & $\checkmark$ & $\checkmark$ & $\checkmark$ & $\checkmark$ & $\checkmark$ & $\checkmark$ & $\checkmark$ & $\checkmark$ & $\checkmark$ & $\checkmark$ & $\checkmark$ & $\begin{array}{l}\checkmark \\
\checkmark\end{array}$ \\
\hline Shape & $\begin{array}{c}\text { Square } \\
\text { Rectangular } \\
\text { Sphere } \\
\text { Circular } \\
\text { Ellipse } \\
\text { Donut } \\
\text { Round box } \\
\text { Mushroom }\end{array}$ & $\checkmark$ & $\checkmark$ & $\checkmark$ & $\checkmark$ & $\checkmark$ & $\checkmark$ & $\checkmark$ & $\checkmark$ & $\checkmark$ & $\begin{array}{l}\checkmark \\
\checkmark\end{array}$ & $\checkmark$ & $\checkmark$ & $\begin{array}{l}\checkmark \\
\checkmark\end{array}$ & $\begin{array}{l}\checkmark \\
\checkmark \\
\checkmark \\
\checkmark \\
\checkmark \\
\checkmark\end{array}$ & $\begin{array}{l}\checkmark \\
\checkmark \\
\checkmark \\
\checkmark\end{array}$ \\
\hline $\begin{array}{l}\text { Number } \\
\text { Width }\end{array}$ & $\begin{array}{l}\text { f concrete rib } \\
\text { concrete rib }\end{array}$ & & & & & & & & & & & & & & & $\begin{array}{l}\checkmark \\
\checkmark\end{array}$ \\
\hline
\end{tabular}

\section{ACKNOWLEDGEMENT}

This work was supported by the Research Grants of University College of Technology Sarawak, UCTS/RESEARCH/2/2018/02.

\section{REFERENCES}

[1] Mohamad, S.Y. and Ramli, A. 2012. Reinforced Concrete Design to Eurocode 2. Malaysia: University Teknologi Malaysia.
[2] Bubble Deck Construction Sdn Bhd. 2018. Bubble Deck FAQ. [Online] Available at: <https://bubbledeck.com.my/reference-faq.html>. [Accessed February 3, 2018].

[3] Ajeel, A.E., Qaseem, T.A. and Rasheed, S.R. 2018. Structural Behavior of Voided Reinforced Concrete Beams under Combined Moments. Civil and Environmental Research, 10(1), 17 - 24.

[4] Ahmad, J.H.A. and Hadi, N.G.M. 2014. Structural Behavior of Reinforced Concrete Hollow Beams under Partial Uniformly Distributed Load. 
International Journal of Engineering, 20, 130 145.

[5] Chung, J.H., Jung, H.S., Bae, B.I., Choi, C.S. and Choi, H.K. 2018. Two-Way Flexural Behavior of Donut-Type Voided Slabs. International Journal of Concrete Structures and Materials, 12(1), 26.

[6] Sivaneshan, P. and Harishankar, S. 2017. Experimental Study on Voided Reinforced Concrete Beams with Polythene Balls. In: IOP Conference Series: Earth and Environmental Science, 6 - 8 October 2017, Cyprus. Famagusta: IOP Publishing, $1-8$.

[7] Wariyatno, N.G., Haryanto, Y. and Sudibyo, G.H. 2017. Flexural behavior of precast hollow core slab using PVC pipe and Styrofoam with different reinforcement. Procedia engineering, 171, 909916.

[8] Anju, V. and Joseph, B.M. 2016. Experimental and Numerical Studies on Reinforced Concrete Hollowcore Sandwich Beams. International Journal of Innovative Research in Science, Engineering and Technology, 5(8), 14730 14737.

[9] Kumar, A. S. and Joy, A. 2015. Experimental Investigation on Partial Replacement of Concrete below Neutral Axis of Beam. International Journal of Science and Research, 4(8), 1670 - 1674.

[10] Manikandan, S., Dharnar, S. and Robertravi, S. 2015. Experimental Study on Flexural Behaviour of Reinforced Concrete Hollow Core Sandwich Beams. International Journal of Advance Research in Science and Engineering, 4(1), 937 - 946.

[11] Izzat, A.F, Farhan, J.A, and Allawi, N.M. 2014. Behaviour and Strength of One Way Reinforced Concrete Slabs with Cavities. International Conference for Engineering Science, University of Mustansiriyah, Baghdad, Iraq, 100-115.

[12] Jesudhason, W.G. and Hemalatha, G. 2014. Experimental Investigation on Beams Partial Replacement below the Neutral Axis. In: National Conference on Technological Innovations in Structural Engineering, 567 - 898.

[13] Joy, J. and Rajeev, R. 2014. Effect of Reinforced Concrete Beam with Hollow Neutral Axis. International Journal for Scientific Research and Development, 2(10), 341 - 348.

[14] Ibrahim, A.M., Ali, N.K. and Salman, W.D. 2013. Flexural Capacities of Reinforced Concrete Twoway Bubbledeck Slabs of Plastic Spherical Voids. Diyala Journal of Engineering Sciences, 6(2), 9 20.

[15] Chung, J.H., Choi, H.K., Lee, S.C. \& Choi, C.S. 2011. Shear Capacity of Biaxial Hollow Slab with Donut Type Hollow Sphere. Procedia Engineering, 14, $2219-2222$.
[16] Chung, J.H., Park, J.H., Choi, H.K., Lee, S.C. and Choi, C.S. 2009. An analytical study on the impact of hollow shapes in bi-axial hollow slabs. Fracture Mechanics of Concrete and Concrete Structures, 30(100), 1729 - 1736.

[17] Malaysian Standard Eurocode 2. 2010. Design of Concrete Structures, MS EN 1992-1-1:2010. Malaysia: Department of Standards Malaysia.

[18] Subramanian, K. and Bhuvaneshwari, P. 2015. Finite Element Analysis of Voided Slab with High Density Polypropylene Void Formers. International Journal of ChemTech Research, 8 (2), $746-753$. 